\title{
Three Canal Mandibular First and Second Premolars: A Treatment Approach. A Case Report
}

\author{
Sashi Nallapati, BDS
}

\begin{abstract}
Mandibular premolars have earned the reputation for having aberrant anatomy. The occurrence of three canals with three separate (type $V$, Vertucci) foramina in mandibular premolars is very rare. If one is to treat mandibular premolar teeth with three canals predictably, it is necessary to be aware of their clinical and radiographic anatomy. These teeth may also require special shaping and obturating techniques. This article reports and discusses the treatment recommendations for an unusual occurrence of three canals with three separate foramina in both the first and second mandibular premolars in the same patient.
\end{abstract}

\section{Key Words}

Three canal mandibular first and second premolars, three foramena, treatment approach

From the Department of Endodontics, Nova Southeastern University, Fort Lauderdale, Florida.

Address requests for reprint to Dr. Sashi Nallapati, $3200 \mathrm{~S}$. University Drive, Fort Lauderdale, FL 33328. E-mail address: sashi@cwjamaica.com.

Copyright (C) 2005 by the American Association of Endodontists
Co: onsistent, high levels of success in endodontic treatment require an understanding of root canal anatomy and morphology. To achieve endodontic success, the entire root canal system must be debrided, disinfected and obturated. The clinician must have a thorough understanding of normal anatomy, and of common variations from the norm. The clinician must also be prepared to identify those teeth that tend to vary greatly from the norm, e.g. mandibular premolars.

Quite a few studies were published in endodontic literature that studied the common reasons for endodontic failures (1-3). Hoen and Pink found a $42 \%$ incidence of missed roots or canals in the teeth that needed retreatment in their investigations (4). They concluded that the clinical application of a thorough knowledge of canal anatomy and meticulous attention to treatment detail are essential to minimizing failure and the need for subsequent endodontic retreatment.

In a series of studies on extracted teeth Vertucci in the 1970s and 1980s determined canal numbers and configurations by percentages for each of the teeth (5). Vertucci's data may not be exactly representative of different locations and ethnic groups, but it is a good starting point for understanding root canal anatomy.

Mandibular premolars have gained a reputation for having aberrant anatomy. Different studies have looked at the root canal morphology of mandibular premolars over the years and reported a fairly high percentage of these teeth to have more than one canal (6-9).

There seems to be a racial predisposition for the presence of two or more canals in maxillary and mandibular premolars $(10,11)$, as well as their bilateral occurrence (12). The occurrence of three canals with three separate (type $V$, Vertucci) foramina in mandibular premolars is very rare. Vertucci and Zillich et al. reported the occurrence of three canals in mandibular first premolars at $0.5 \%$ and $0.4 \%$ respectively. Their studies in second premolars showed these percentages at $0.0 \%$ and $0.4 \%$, respectively $(13,14)$.

If one is to treat mandibular premolar teeth with three canals, predictably, it is necessary to be aware of their clinical and radiographic anatomy. These teeth may also require special shaping and obturating techniques.

The purpose of this article is to report, as well as discuss, treatment recommendations for an unusual occurrence of three canals with three separate foramina in both the first and second mandibular premolars in the same patient.

\section{Gase Report}

A 49 yr-old White Jamaican male with a noncontributory medical history was referred to the author's private practice for endodontic treatment on the right mandibular first and second premolars by his general dentist.

The chief complaint of the patient was "pain in the lower right back teeth." Clinical examination revealed restorations in the right mandibular first and second premolar teeth $(28,29)$ with distal caries in 29 . Teeth 30 and 31 were missing and 32 drifted mesially. Teeth 28 and 29 tested percussion sensitive. Vitality tests on both teeth showed no response to cold and EPT. Radiographic examination revealed periradicular radiolucencies in relation to 28 and 29. More than one root canal was suspected in both the premolars (Fig. 1A).

A pulpal diagnosis of necrotic pulp and a periradicular diagnosis of acute exacerbation of a chronic periradicular periodontitis were made. Nonsurgical endodontic treatment was planned in both 28 and 29 over two visits with the use of calcium 

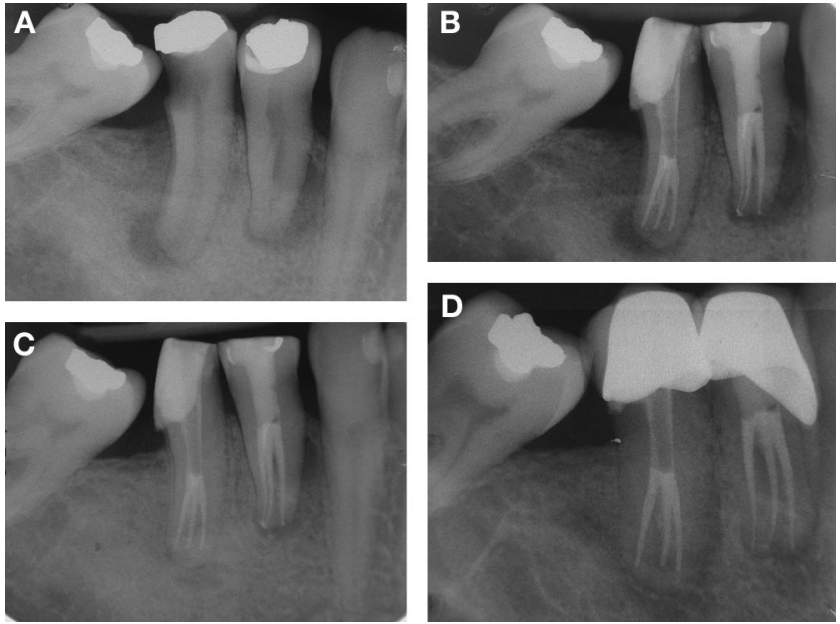

Figure 1. (A) Three canal first and second mandibular premolars with periapical lesions. $(B)$ Immediate postoperative radiograph shows three canals with three apical portals of exit. Notice the composite post in 28 and fiber post in 29. (C) A 5 month recall shows dramatic healing. (D) A 2 yr recall shows complete healing.
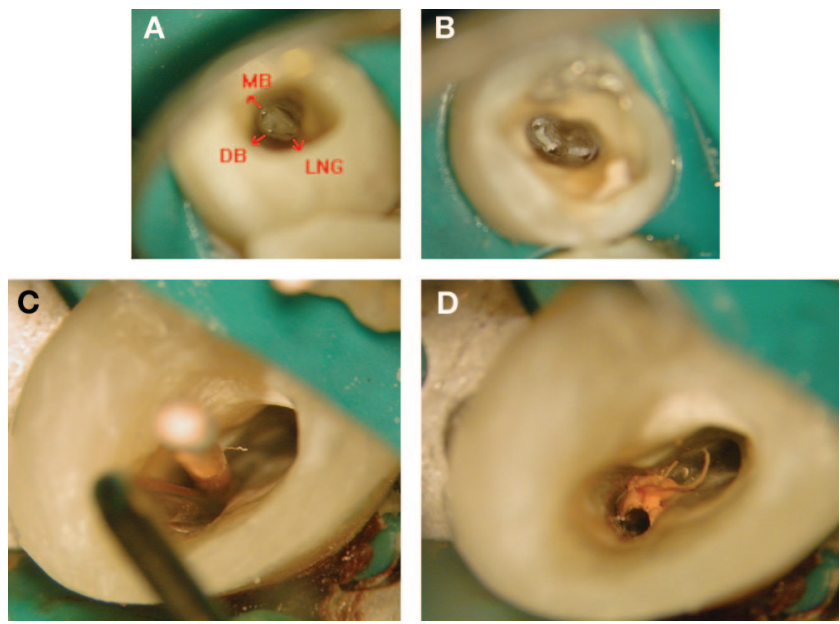

Figure 2. (A) Access reveals one main canal with a trifurcation at the mid root level. $(B)$ Two buccal canals and one lingual canal were enlarged with Gated Glidden drills. $(C)$ Plugger placed in the mesiobuccal canal while obturating the mesiolingual canal. $(D)$ Plugger prevented the accidental blocking of the mesiobuccal canal with gutta-percha while obturating the mesiolingual canal.

hydroxide as inter-appointment, intra-canal medicament. A surgical operating microscope was to be used for the entire treatment.

After the administration of the local anesthetic (2\% Lignocaine with 1:100,000 epinephrine), under rubber dam isolation both 28 and 29 were accessed. On entry into the pulp chamber of 28 and 29, one main canal orifice was found which split into three different canal orifices at the mid- root level (Fig. $2 A, B$ ). Mesiobuccal, distobuccal and lingual canals were identified. Gates Glidden drills 4, 3, 2, with a brushing motion were used in a crown down fashion to enlarge the main orifice to the level of the trifurcation to obtain straight line access to all the three canals. Also used alternately as irrigants was 5.25\% sodium hypochlorite, 17\% EDTA, and 200\% alcohol. Working length was established with the use of an Apex locator (Root ZX, J. Morita Inc). The canals were cleaned and shaped with hand $\mathrm{K}$ files and nickel titanium rotary files (k3, Sybron Endo.com).
Patency was achieved in all the canals and was maintained with a $10 \mathrm{k}$ file. All the canals had separate portals of exit. Calcium Hydroxide (Ultracal, Ultradent.com) was used as intracanal medicament and the access cavities were sealed with cavit and IRM between appointments. The patient was seen after $4 \mathrm{wk}$ for the completion of the treatment. All the symptoms had ceased. Calcium hydroxide was removed from the canals with ultrasonic activation of 17\% EDTA and 5.25\% hypochlorite. After drying the canals with paper points, they were fit with nonstandardized gutta-percha points. Kerr's pulp canal sealer was used as the root canal sealer. Each of the canals was obturated with warm vertical condensation technique. A dual-cure composite restoration (Permaflo DC, Ultradent.com) was used as a composite post and core in tooth 28 . A fiber post (Dentatus.com) was cemented with dual-cure composite and a composite core was placed in tooth 29. Patient was advised to get these teeth crowned as soon as possible (Fig. $1 B$ ).

At the 5 month recall, patient was asymptomatic. Radiographs revealed dramatic healing (Fig. 1C). Two year recall radiograph showed complete healing (Fig. $1 D$ ).

\section{Discussion}

Accurate preoperative radiographs, straight and angled, using parallel technique are essential in providing clues as to the number of roots that exist (15).

In mandibular premolars with three canals, the cervical half of the root is generally wider than usual, with little or no taper. Root canals may not be evident radiographically or may look unusual. Root canal space may disappear halfway through the roots. Careful interpretation of the periodontal ligament space may suggest the presence of an extra root or canal. Mesial and distal angled views will often reveal the presence of a bi/trifurcation of the root canal. Clinical presentation is frequently atypical. Gingival recession may reflect the furcal morphology in these teeth and thus hint at the presence of two buccal roots. Probing the buccal sulcus to feel the root eminences and furcal anatomy may also help to identify the presence of two buccal roots if present.

The use of magnification and fiber optic illumination offers a tremendous advantage in locating and treating 'extra' canals (16). The Surgical Operating Microscope has been found to be particularly helpful. It is most important to be on the look out for additional canals.

Optimum opening of the access cavity is absolutely necessary. During the initial placement of scouting files (hand k files 6, 8, or 10) in the main canal, one may encounter an obstruction and the file may deflect to the buccal or lingual before it travels any further. This may indicate a canal division. It is important, thereafter, to develop a sense of tactile feel and direction with appropriately precurved scouting files to detect the trifurcation.

When working with the surgical operating microscope, one can many times see the hypochlorite bubbling in the extra canal, marking its presence. On occasion, dyes or trans-illumination may be helpful in locating additional canals (17).

Once it has been established that there are three canals, it is important to obtain straight line access to all the canals. This may be achieved by Gates-Glidden drills 4, 3, and 2 set on a slow hand piece rotating at 750 to $1000 \mathrm{rpm}$ utilized in a crown down fashion. These drills should be withdrawn against the canal walls and away from the root concavities. This will reduce stress on the files used subsequently to shape the canals and minimize the risk of instrument separation and canal transportation.

The working length may be determined using radiographs and electronic apex locators. Small, slightly pre-curved k- files or nickeltitanium hand files are used to debride the canals and to establish a glide path to the working length. 
Despite the existence of complicated dental anatomy, shaping outcomes with nickel-titanium instruments are mostly predictable (18). Cautious use of rotary or hand nickel-titanium files prepares the canals to a predetermined shape. After gauging the apical third of the canals, additional preparation is performed, if necessary, before obturation. After the master cones are selected and fit, the canals are dried with paper points. A heat carrying plugger (Touch ' $\mathrm{N}$ Heat, sybronendo.com), that binds 4 to $5 \mathrm{~mm}$ short of the working length, is prefitted for each canal. Leave a plugger in place to keep the canal patent while the canal adjacent is being obturated (Fig. 2C,D). The use of vertical compaction with apical backfilling technique has shown to allow the creation of an effective apical plug and an excellent adaptation of backfilling to apical gutta-percha and to root canals (19). Using this technique, seat the master cone and sever it with multiple heat bursts to below the level of division of the canals. Remove the plugger that was in the adjacent canal and place the other master cone with sealer and repeat the procedure just discussed. Repeat the same in the third canal. Insert the prefitted heat carrying plugger into each of the three canals, activate it, and down pack to within $5 \mathrm{~mm}$ of the apex. Backfill each of the canals to the level of bifurcation with the Obtura II (Obtura Corp, Fenton, MO) and compact the warm gutta-percha with hand pluggers. The rest of the canal space is obturated as a single canal with Obtura II.

Successful and predictable endodontic treatment requires knowledge of biology, physiology and root canal anatomy. It also requires proper instruments and the knowledge to use these instruments effectively. Teeth with extra roots and/or canals pose a particular challenge. This article discusses how to identify mandibular premolars with three canals and some modifications to standard clinical techniques that can help produce successful treatment outcomes.

\section{Acknowledgment}

The author wishes to thank Dr. Dudley Chai-Onn, DDS, for his help with the revision of the manuscript.

\section{References}

1. Seltzer S, Bender IB, Smith J, Freedman I, Nazimov H. Endodontic failures: an analysis based on clinical, roentgenographic, and histologic findings. II. Oral Surg Oral Med Oral Pathol 1967;23:517-30.

2. Swartz DB, Skidmore AE, Griffin JA Jr. Twenty years of endodontic success and failure. J Endod 1983;9:198-202

3. Vire DE. Failure of endodontically treated teeth: classification and evaluation. J Endod 1991;17:338-42.

4. Hoen MM, Pink FE. Contemporary endodontic retreatments: an analysis based on clinical treatment findings. J Endod 2002;28:834-6.

5. Vertucci FJ. Root canal anatomy of the human permanent teeth. Oral Surg Oral Med Oral Pathol 1984;58:589-99.

6. Barrett MT. The internal anatomy of teeth with special reference to the pulp and its branches. Dental Cosmos 1925;67:581-92.

7. Amos ER. Incidence of bifurcated root canals in mandibular bicuspids. J Am Dent Assoc 1955;50:70-1.

8. England MC Jr, Hartwell GR, Lance JR. Detection and treatment of multiple canals in mandibular premolars. J Endod 1991;17:174-8.

9. Baisden MF, Kulild JC, Weller RN. Rootcanal configuration of the mandibular first premolar. J Endod 1992;18:505-8.

10. Nallapati S. Three-canal Maxillary premolars: a common clinical reality, Endodontic Practice 2003;6:3:22-27.

11. Trope M, Elfenbein L, Tronstad L. Mandibular premolars with more than one root canal in different race groups. J Endod 1986;12:343-5.

12. Sabala CL, Benenati FW, Neas BR. Bilateral root or root canal aberrations in a dental school patient population. J Endod 1994;20:38-42.

13. Vertucci FJ. Root canal morphology of mandibular premolars. J Am Dent Assoc 1978;97:47-50.

14. Zillich R, Dowson J. Root canal morphology of mandibular first and second premolars. Oral Surg Oral Med Oral Pathol 1973;36:738-44.

15. Silha RE. Paralleling long cone technic. Dent Radiogr Photogr 1968;41:3-19.

16. Carr GB. Microscopes in endodontics. J Calif Dent Assoc 1992;20:55-61.

17. Nallapati S, Glassman G. Ophthalmic dyes for root canal location. Endodontic Practice 2004; 7:21-26.

18. Peters OA. Current challenges and concepts in the preparation of root canal systems: a review. J Endod 2004;30:559-67.

19. Venturi M, Breschi L. Evaluation of apical filling after warm vertical gutta-percha compaction using different procedures. J Endod 2004;30:436-40. 